\title{
Comparative Study of Endometriallavage, Dilatation And Curettage with Hysterectomy in Women with Perimenopausal/Postmenopausal Bleeding
}

\author{
Dr. Rama Krishnaswamy ${ }^{1}$, Dr.N.V.Vanitha ${ }^{2}$ \\ (Professor, Department Of Pathology,ISO\&Govt.Kasturba Gandhi Hospital/Madras Medical College, India) ${ }^{l}$ \\ (Assistant Professor, Department Of Pathology, Madras Medical College) $)^{2}$
}

\begin{abstract}
Endometrial carcinoma is third common genital malignancy in India. Endometrial tissue sampling is most common diagnostic procedure in the assessment of women with abnormal uterine bleeding. Over the years many methods were used to obtain endometrial samples. The safety and simplicity of the procedures influence the extent to which they are employed. Endometrial lavage is less invasive and safe outpatient procedure to obtain endometrial samples for cytological diagnosis. The aim of our study is to evaluate endometrial lavage as an alternative to dilatation and curettage to obtain adequate endometrial sample, this study is done over a period of 3 years in 50 perimenopausal /postmenopausal women who attended the outpatient department with complaints of abnormal uterine bleeding. Endometrial lavage is done using manual vacuum aspirator and normal salineas an outpatientprocedure. Thematerial obtained is centrifuged, smears prepared from the sediment for cytological study and stained with hematoxylin and eosin. Later dilatation and curettage and hysterectomy is done and the resultscompared. The correlation between endometrial lavage and hysterectomy is $74 \%$, dilatation and curettage with hysterectomy is $82 \%$.
\end{abstract}

Keywords:Abnormal uterine bleeding, Cytology, Dilatation and curettage,Endometrial lavage

\section{Introduction}

Endometrial carcinoma is the most common malignancy of female genital tract indevelopedcountries. ${ }^{[1]}$ The incidence of endometrial carcinoma is third amongst genital malignancy next to cervix and ovary in India. Histopathological examination of endometrial tissue remains standard diagnostic procedure for uterine abnormalities, against which the performances of all new diagnostic tools for evaluating the endometrium are compared. Endometrial tissue sampling is one of the most common diagnostic procedure in the assessment of women with abnormal uterine bleeding, accurate diagnosis helps the implementation of optimal treatment strategies. Until recent times usual methods of evaluating abnormal uterine bleeding was dilatation and curettage, but this detects the cause in less than $50 \%$ of cases. The procedure requires general anesthesia and has complications, Such as uterine perforation, hemorrhage and infection, Papanicolaou and Traut reported that carcinoma of corpus uteri can be detected by means of cytological examination of the vaginal and cervical secretions. ${ }^{[2]}$ In order to obtain well preserved cells from the uterine cavity it is necessary to use intra uterine aspiration and it represents the most efficient procedure for cytological diagnosis of adenocarcinoma of endometrium. ${ }^{[3]}$ One of the earlier devices was a simple endometrial aspiration cannula. The cannula was used as an office instrument on high risk patients and led to the discovery of a number of occult endometrial hyperplasias and carcinomas. ${ }^{[4]}$ The main aim of our study is to evaluate simple endometrial sampling method endometrial lavage as an alternative to dilatation and curettage to secure an adequate sample of endometrium, without causing much discomfort to the patients.

\section{Materials and methods}

This study has been undertaken in 50 perimenopausal / post-menopausal women aged $\geq 40$ years, who attended the outpatient department in our hospitalwith abnormal uterine bleeding, over the period of 3 years. All patients signed informed consent prior to the procedures and the study protocol confirmed to the guidelines of the Institutional Ethical Committee. Patients with acute vaginal or cervical infection, pelvic inflammatory disease or clotting disorders are not selected for the study. Endometrialsampling is doneby endometrial lavage using manual vacuum aspirator and $2 \mathrm{ml}$ normal saline as a day care procedure ${ }^{[5]}$ and patients admitted for dilatation and curettage. The specimen obtained is centrifuged for $10 \mathrm{~min}$ at $2500 \mathrm{rpm}$, sediment spread on the slides, fixed in $95 \%$ ethonol and stained with hematoxylin and eosin. ${ }^{[6]}$

The cytological smears are studied on the basis of number of epithelial cell clusters, cellularmakeup, cohesiveness of cells and nuclear characteristics. ${ }^{[7],[8]}$ They are categorized into normal (proliferative phase /secretory phase) andabnormal (hyperplasia / endometrial carcinoma). Thehistopathological diagnosis is based on systematic examination of gland to stroma ratio, glandular features, stromal features , appearance of vessels 
and pattern of uniformity ${ }^{[9]}$ They are classified asnormal (proliferative phase/ secretory phase/atrophy) and abnormal (disordered proliferative phase/ hyperplasia/ endometrial carcinoma). When the material is insuffient for examination, they are categorized as inadequate. Both the diagnoses are compared with histopathological findings of hysterectomy as gold standard. The results are statistically analyzed using sensitivity,specificity,predictive value of positive test, predictivevalue of negative test and diagnostic accuracy.

\section{Results}

The study is done in 50 cases, of which 40 are perimenopausal 10 are post menopausal, the age ranged from 40-80years with mean age of 45years, the mean duration of abnormal uterine bleeding is 4 months, the mean parity is 3.In cytological diagnosis of endometrial lavage the normal findings are $80 \%$,endometrial carcinoma $6 \%$ and inadequate samples $14 \%$. The findings in histopathological examination of D\&C specimens are normal $70 \%$,disordered proliferative phase $6 \%$,hyperplasia $2 \%$,endometrial carcinoma $8 \%$ and inadequate samples $14 \%$.Histopathological findings in hysterectomy are normal $80 \%$,disordered proliferative phase $8 \%$,hyperplasia4\% and endometrial carcinoma8\%.

\section{Discussion}

Endometrial tissue sampling is one of the most common diagnostic procedures in gynecology and the primary indication is in the assessment of women with abnormal uterine bleeding. The main objective of endometrial sampling in perimenopausal and post menopausal patients with abnormal uterine bleeding is detecting premalignant or malignant endometrial disease. The sampled material can be examined by cytological or histological examination. The direct endometrial sample obtained for cytological examination by endometrial lavage provides cells from areas of uterine cavity where the cannula or catheter may not reach readily.

In cytology normal findings showed $85 \%$ correlation, endometrial carcinoma showed $75 \%$ correlation. The overall correlation in cytology is $74 \%$. Disordered proliferative phase and hyperplasia are not reported in cytology due to inadequate diagnostic criteria. Out of the 40 cases diagnosed as normal by hysterectomy, 34 casesare the same in cytology, the remaining 6 cases are reported as inadequate. The 4 cases reported as disordered proliferative phase in hysterectomy, are not diagnosed in cytology, of the 4 cases 3 cases are reported as proliferative phase and one as inadequate, 2 cases of hyperplasia reported in hysterectomy are not diagnosed by cytology, and they are reported as proliferative phase. 4 cases of endometrial carcinoma are diagnosed by hysterectomy, in 3 cases the diagnosis is same in cytology, and the remaining one is reported as proliferative phase.

In $\mathrm{D} \& \mathrm{C}$ normal findings showed $85 \%$ correlation, disordered proliferative phase and hyperplasia correlated in 50\% of cases, endometrial carcinoma correlated in all the 4 cases showing $100 \%$ correlation. The overall correlation in D\&C is $82 \%$.In histopathological examination of hysterectomy, 40 cases are reported as normal, in the HPE in D \&C 34 cases are reported the same. In the remaining 6 cases, Disordered proliferative phase is reported in one case and 5 cases are reported inadequate .Out ofthe 4 cases reported as disordered proliferative phase in hysterectomy 2 cases correlated with $\mathrm{D} \& \mathrm{C}$ one case is reported as proliferative phase and the other one is reported as inadequate .In hysterectomy hyperplasia is reported in 2 cases, one case is reported the same in D\&C, the other one is reported as inadequate .Endometrial carcinoma is reported in 4 cases of hysterectomy specimens, all the 4 cases reported the same in D\&C.

The cytological findings in endometrial lavage correlated with 3 cases of endometrial carcinoma. One case is not diagnosed by endometrial lavage, which is a focal lesion. In D\&C all the four cases are diagnosed. There are no false positive reports.

In the present study cytology of endometrial lavage showed sensitivity of $75 \%$, specificity of $100 \%$, positive predictive value of $100 \%$, negative predictive value of $98.87 \%$ and the diagnostic accuracy of $98 \%$ for the diagnosis of endometrial malignancy. D\&C showed $100 \%$ sensitivity, specificity, positive predictive value, negative predictive value and diagnostic accuracy for endometrial carcinoma.

The incidence of endometrial carcinoma ranged from $7.5 \%$ to $9 \%$ in various studies, ${ }^{[10],[11],[12]}$ Antoni et al reported maximum number of cases about $9 \%{ }^{[13]}$, and inour study incidence is $8 \%$.carcinoma.

In endometrial lavage Schei et al reported very low sensitivity of $25 \%$ and specificity of $99 \%{ }^{[14]}$.In other studies sensitivity ranged from $50 \%$ to $81 \%$, specificity is $100 \%{ }^{[15,16]}$, in our study sensitivity is $75 \%$ and specificity is $100 \%$. D\&C shows varied sensitivity and specificity in different studies, Ceci et al reported sensitivity of $46 \%$, specificity of $100 \% .{ }^{[17]}$ Yarandiet al in their study reported $30.2 \%$ sensitivity, $72.3 \%$ specificity. ${ }^{[18]}$ Our study shows $100 \%$ sensitivity and specificity.

\section{Conclusion}

Minimally invasive procedure endometrial lavage is simple, safe and acceptable technique in diagnosing endometrial cancer in women with premenopausal/post-menopausal bleeding. Accuracy is lower in detecting endometrial hyperplasia. 
VI. Tables

Table 1.Cytology and Histopathology in hysterectomy correlation

\begin{tabular}{|l|l|l|l|l|}
\hline \multicolumn{2}{|l|}{ Findings } & HPE in hysterectomy & $\begin{array}{l}\text { Cytology } \\
\text { (Endomertial } \\
\text { lavage) }\end{array}$ & \%Correlation \\
\hline \multirow{2}{*}{ Normal } & $\begin{array}{l}\text { Proliferative Phase/ Secretory Phase/ } \\
\text { Atrophy }\end{array}$ & 40 & 34 & $85 \%$ \\
\hline \multirow{2}{*}{ Abnormal } & Disordered proliferative phase & 4 & - & - \\
\cline { 2 - 6 } & Hyperplasia & 2 & - & - \\
\cline { 2 - 6 } & Endometrial carcinoma & 4 & 3 & $75 \%$ \\
\hline Total & & 50 & 37 & $74 \%$ \\
\hline
\end{tabular}

Table 2.Histopathology in D\&C and Hysterectomy correlation

\begin{tabular}{|l|l|l|l|l|}
\hline \multicolumn{2}{|l|}{ Findings } & $\begin{array}{l}\text { HPE in } \\
\text { hysterectomy }\end{array}$ & HPE in D\&C & $\%$ Correlation \\
\hline Normal & $\begin{array}{l}\text { Proliferative Phase/ } \\
\text { Secretory Phase/ Atrophy }\end{array}$ & 40 & 34 & $85 \%$ \\
\hline Abnormal & $\begin{array}{l}\text { Disordered proliferative } \\
\text { phase }\end{array}$ & 4 & 2 & $50 \%$ \\
\cline { 2 - 5 } & Hyperplasia & 2 & 1 & $50 \%$ \\
\cline { 2 - 5 } & Endometrial carcinoma & 4 & 4 & $100 \%$ \\
\hline Total & 50 & 41 & $82 \%$ \\
\hline
\end{tabular}

\section{VII.Figures}

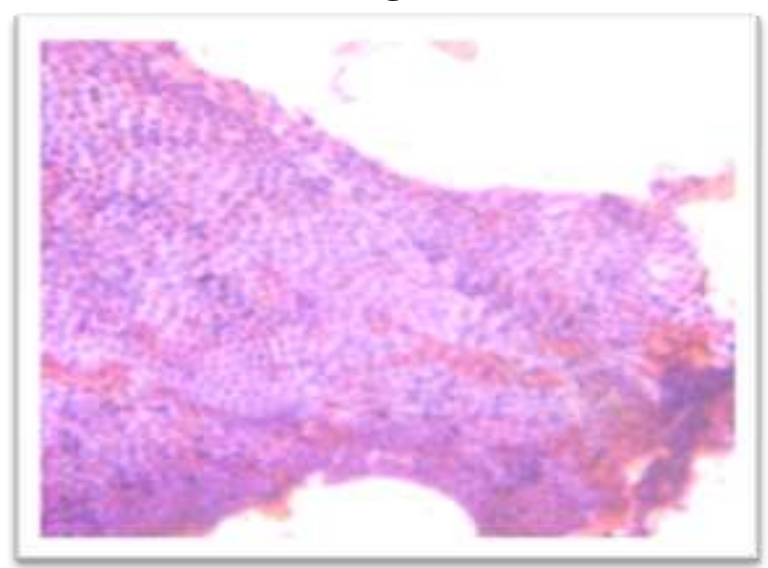

Fig. 1. Proliferative phase-Cytology,Endometrial glandular cells arrangedin cohesive honey comb type sheets(H\&E400X)

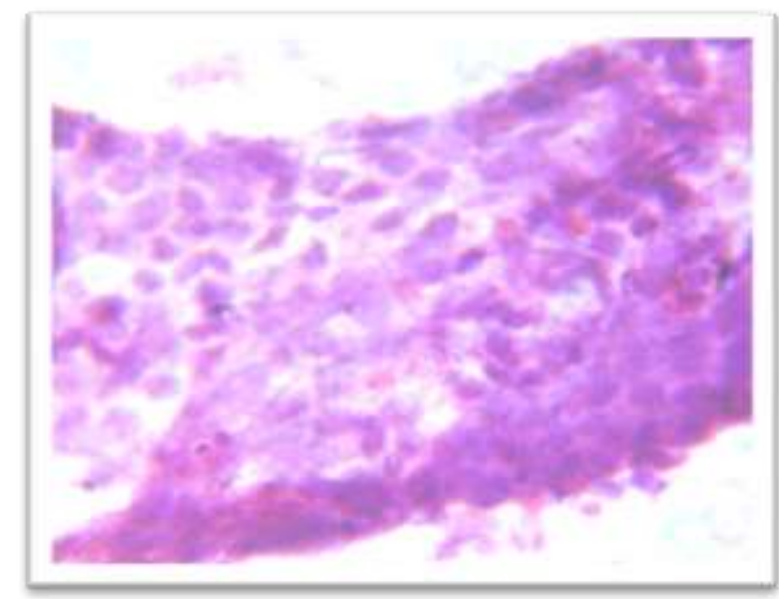

Fig.2.Secretory phase-Cytology, Endometrial cells with clearvacuolated cytoplasm(H\&E 1000X) 


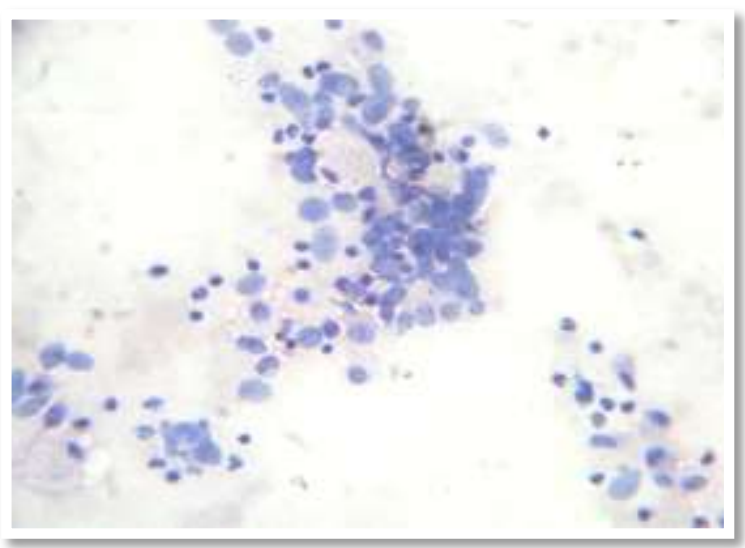

Fig.3.Endometrial carcinoma-cytology, Loosely cohesive clusters and singly scattered malignant cells with inflammatory cells(H\&E400X)

\section{References}

[1]. Ferlay, J., Soerjomataram, I., Dikshit, R., Eser, S., Mathers, C., Rebelo, M., Parkin, D. M., Forman, D. and Bray, F. (2015), Cancer incidence and mortality worldwide: Sources, methods and major patterns in GLOBOCAN 2012. Int. J. Cancer, 136 : E359-E386. doi: $10.1002 /$ ijc. 29210

[2]. Papanicolaou, G.N. and Traut. H.F. Diagnosis of uterine cancer by the vaginal smear. Newyork the Commonwealth fund. 1943 .

[3]. Winner, M.L., Gunn, S.A. and Ayre J.E; Cyto diagnosis of endometrium; new, simple office procedure Obst. \&Gynec, 5: 279-282, 1955 .

[4]. Jordan MJ, Bader GM, Namazic AS, comparative accuracy of pre operative cytological and histological diagnosis in endometrial lesions. ObstetGynecol 7: 646-653, 1956.

[5]. Hemlatha AN, Pai MR, Raghuveer CV. Endometrial aspiration cytology in dysfunctional uterine bleeding. Indian J PatholMicrobiol 2006; 49:214-7.

[6]. ReeniMalik,RenuAgarwal,PuneetTandon, Cytological assessment of endometrial washings obtained with an insemination cannula and its histological correlation. Journal of cytology vol.25, No24October to December, 2008, pp128-132

[7]. Leopold G.Koss, Myron R. Melamed,Koss' Diagnostic Cytology and Its Histopathologic Bases, 5thEdition, (Lippincott Williams \&Wilkins, 2006) Chapter13

[8]. MarluceBibbo,David C Wilbur, Comprehensive Cytopatology, Third Edition, (Saunders Elsevier,2008)

[9]. Chapter 10

[10]. Robert J. Kurman, Lora Hedrick Ellenson and Brigitte M. Ronnett,Blaustein's Pathology of the Female Genital Tract,Sixth Edition(New York Dodrecht Heidelberg London,Springer, 2011)

[11]. Phua SM, Lob SF, Chou SY. Outpatient diagnosis of endometrial sampling Int J GynecolObstet 1992; 39: 336-7.

[12]. Guerreiro IDC, de oliveralima PR, Baracat FF. Endometrial biopsy with uretral plastic no-12 sound Sao Paulo med J 1995; 113 : 698-700.

[13]. Goldberg GL, Tsalacopoulos G, Davey DA. A comparison of endometrial sampling with the accurette and vabra aspirator and uterine curettage. SA med J 1982; 23: 114-6.

[14]. Antoni J, Folch E, Costa J, Foradada CM, Cayyela E, Combalia N, et al. Comparison of cytospat and pipelle endometrial biopsy instruments. Eur J ObstetGynacol 1997; 72: 57-61.

[15]. Schei B, bang TF, Halgonset J, Haugen OA, Haarstad I, on sound M. Microcurettage Sampling of the endometrium for histopathological examination. ActaObstetGynecolScand 1994; 73: 497-501.

[16]. Costa MM, Einhorn N, Sjovall, Ryde E, Nasiell M, Roger V, et al Endometrial Carcinoma diagnosed by the gynoseann method. ActaObstetGynecolScand 1986; 65: 473-5.

[17]. Kufahl J, Pedersen I, Eriksen PS, Helkjaer PE, Plassen LG, Jensen KL, et al TVUS, endometrial cytology sampled by Gynoscan and histology obtained by uterine explora curette compared to the histology of the uterine specimen. ActaobstetGynecolScand 1997; 76: 790-6.

[18]. OrandoCeciMD,StefenoBettochi MD, Comparison of hysteroscopicand hysterectomy findings for assessing the diagnostic accuracy of office hysteroscopy..Fertility\& Sterility, Vol 78, No.3, Sept 2002.

[19]. YarandiF,Izadi Mood N,Diagnostic accuracy of dilatation and curettage for abnormal uterine bleeding .ObstetGynaecol Res.2010 Oct;36(5):1049-52 